\title{
Comparison between qualitative rockfall risk rating systems for a road affected by high traffic intensity
}

\author{
P. Budetta and M. Nappi \\ Department of Civil, Architectural and Environmental Engineering, University of Naples "Federico II", Piazzale Tecchio, 80, \\ 80125 Naples, Italy
}

Correspondence to: P. Budetta (budetta@unina.it)

Received: 23 October 2012 - Published in Nat. Hazards Earth Syst. Sci. Discuss.: -

Revised: 16 January 2013 - Accepted: 2 May 2013 - Published: 22 June 2013

\begin{abstract}
The paper deals with the assessment of the rockfall risk for a road stretch, in southern Italy, affected by high traffic intensity. Three qualitative rockfall risk rating systems (QRSs) which use an exponential scoring with a base of 3 were employed, and then the results were compared. The used methods are the following: the Rockfall Hazard Rating System, a modified version of this method already proposed in the past by one of the authors, and the modified version of the Colorado Rockfall Hazard Rating System. The studied road stretch is about $11 \mathrm{~km}$ in length and is part of a very tortuous road flanked by rock slopes characterised by complex geostructural and geomechanical layouts. The road was subdivided into 56 sections, defined so as to have - as much as possible - homogeneous geological characteristics. By means of the three QRSs, it was possible to ascertain that high levels of rockfall risks are due to the lack of ditches, a very limited percentage of decision sight distance (PDSD) values and a small roadway width, whereas a subordinate factor is the hazard caused by rockfalls. Several positive and negative aspects arising from the use of the employed methods are highlighted and discussed.
\end{abstract}

\section{Introduction}

Transportation corridors in a great deal of regions are often liable to undergo rockfalls, which cause a major hazard for motorists as well as a large amount of damage and injuries (Bunce et al., 1997; Hungr et al., 1999; Budetta et al., 2005). Over the last two decades, several qualitative risk rating systems (QRSs) have been proposed in order to reduce the potential consequences of rockfalls, and information technology systems (involving the use of electronic data sets, video images, lidar-based technologies, and GIS) have been implemented by several authors and transportation agencies in the USA, Canada, Australia and elsewhere (Pierson et al., 1990; Franklin and Senior, 1997; Bateman, 2003; Rose, 2005; Drumm et al., 2005; Liang et al., 2006; Pack et al., 2007; Youssef and Maerz, 2012; Russell et al., 2008; Mekni et al., 2008; Ferrero et al., 2011; Lato et al., 2012; Mignelli et al., 2012).

A lot of these QRSs invariably use a crude exponential scoring pattern requiring a base of 3 (e.g. 3, 9, 27, 81 or $1,3,9,27,81)$, and the total score reflecting the risk derived from the summation of scores of factors of different quantitative and qualitative categories (the slope height, ditch effectiveness, traffic, geological characteristics, failure magnitude and consequence). In particular the geological characteristics of slopes and cuts are described in an inadequate manner, and the parameters do not always seem appropriate (Hack, 2002; Budetta, 2004; Pantelidis, 2009). Furthermore, this procedure is not consistent with the definition of risk used in the quantitative risk analysis (QRA) (risk $=$ hazard $\times$ consequences), and related results cannot be compared (Pantelidis, 2011).

In order to evaluate the rockfall hazard, we should use probabilistic or deterministic approaches for calculating safety factors of the studied road slopes. As these approaches require several geomechanical and statistical data along many kilometres of road, they are not quick methods. However, the documentation of rockfall activity is commonly poor for most roads or absent for new roads, and complete landslide inventories are rare due to the lack of reporting of small/medium events by companies that manage the roads. 
Furthermore, many variables do not make QRA easy, e.g. simplifying assumptions adopted as regards the traffic and vehicles, disregarding socio-economic consequences due to traffic disruption, empirical or heuristic methods used for the study of correlations between the rockfall frequency and the triggering factors. As a result, a high level of sophisticated calculations is often inadequate with regard to the quality of data input.

QRSs are the most widely used methods because they are "first-level" or "intermediate" characterisation approaches, useful for subsequent detailed geomechanical analyses in well-located areas (Fell et al., 2008). In the international literature there are no investigations concerning the main differences and similarities among these methods. Pantelidis (2011) listed 18 systems and performed a critical review, but he did not make a real comparison applying them to the same road stretch. Consequently, it is difficult to decide what method best suits the local geological and environmental settings. The aim of this paper is therefore to show the results of three qualitative methods: the original Rockfall Hazard Rating System (RHRS) by Pierson et al. (1990), the modified version of RHRS (mRHRS) proposed by Budetta (2004), and the modified Colorado Rockfall Hazard Rating System (CRHRS) proposed by Russell et al. (2008). The studied road stretch belongs to an important road linking some famous tourist resorts in the southern slope of the Sorrento Peninsula (southern Italy) such as Positano, Amalfi and Salerno, the province capital town (Fig. 1). This road is affected by a high traffic intensity because it is the only transportation corridor in this area that, due to its complex geomorphological and geostructural setting, is sometimes affected by rockfalls, which cause damage and road closures.

\section{Methods}

All three methods use an exponential scoring system with a base of 3 , and the risk $(R)$ is given by (Pantelidis, 2011)

$R=f_{\mathrm{m}}+\Sigma f_{\mathrm{h}}+f_{\mathrm{d}}+\Sigma f_{\mathrm{c}}$,

where $f_{\mathrm{m}}, f_{\mathrm{h}}, f_{\mathrm{d}}$, and $f_{\mathrm{c}}$ are factors related to the estimated magnitude of failure (m), the failure hazard $(\mathrm{h})$, the ditch effectiveness (d), and the consequences of a possible failure (c), respectively.

The Rockfall Hazard Rating System (RHRS) was developed at the Oregon Transportation Department and was tested at over 4000 sites along the US motorway system (Pierson et al., 1990; Pierson and van Vickle, 1993; Pierson et al., 2005). The exponential scoring system applies to the hazard factors (slope height, geological characteristics, block size, volume of rockfall per event, climate and presence of water on slope and rockfall history) and to the consequence factors (ditch effectiveness, average vehicle risk, percentage of decision sight distance, roadway width). Some categories are described qualitatively and might lead to ap-

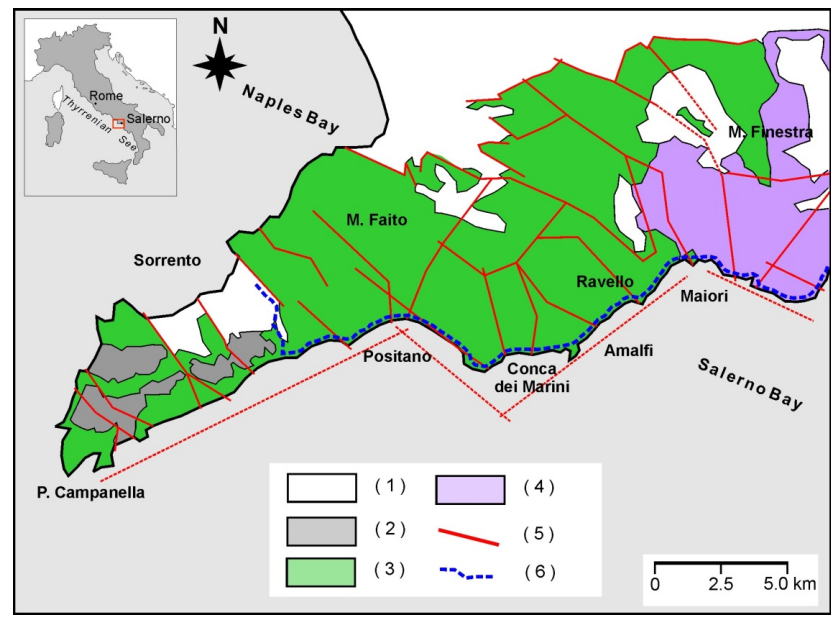

Fig. 1. Geological map of the study area. (1) Alluvial, colluvial and pyroclastic deposits; (2) Miocene silico-clastic deposits; (3) Mesozoic limestones; (4) Mesozoic dolomites; (5) main faults; and (6) the route of the Amalfitana no. 163 state road.

praisals which might be subjective and approximate. Slopes with total scores lower than 300 are classified for remedial work with a low urgency, whereas those higher than 500 need immediate stabilization measures.

In order to make the scoring criteria more objective, Budetta (2004) suggested some modifications for the abovementioned categories. In mRHRS, Romana's slope mass rating (SMR - Romana, 1985, 1988, 1991) for the slope instability hazard evaluation was introduced. Consequently, some parameters were introduced to cover geomechanical features of discontinuities, slope failure modes and cut excavation methods. Another reason for which Romana's classification has been used is to rate the joint spacing and groundwater conditions of outcropping rock masses. On behalf of the JTC1 (Joint Technical Committee on Landslides and Engineered Slopes), Fell et al. (2008) suggested mRHRS as an intermediate characterisation method for cuts and slopes along roads and railways.

The modified version of the Colorado Rockfall Hazard Rating System (CRHRS) was developed at the Colorado Department of Transportation (CDOT) by Russell et al. (2008). Twenty-seven parameters were grouped into four separate categories (slope, climatic, geological, and traffic characteristics) and were added. Depending on the slope lithology, not all of the 27 parameters are used simultaneously. If sedimentary or crystalline rock masses outcrop on the slope 18 parameters must be used, whereas if the dominant lithology is the block-in-matrix material, then only 12 parameters are rated (in such a case discontinuities are obviously not present). As this study deals with sedimentary rocks, specific rating parameters pertinent to these outcropping rock masses were analysed. 
For predicting the total hazard score using fewer parameters than the 18 contained in CRHRS, equations based on the ordered logistic regression of 355 slopes of crystalline, sedimentary and block-in-matrix rocks were developed (Santi et al., 2009). For sedimentary rock masses the following equations were developed, where the predictive total hazard score (PS) is given by (Santi et al., 2009)

i. 6-term equation, valid for cut slopes $(n=43)$ :

$$
\begin{aligned}
\mathrm{PS} & =277.2+1.67(\mathrm{SH})+1.74(\mathrm{RF})+1.78(\mathrm{LF}) \\
& +1.42(\mathrm{AS})+1.63(\mathrm{IN})+1.35(\mathrm{AP}) \\
R^{2} & =83 \%
\end{aligned}
$$

ii. 4-term equation, valid for cut slopes $(n=43)$ :

$$
\begin{aligned}
\mathrm{PS} & =340.1+1.88(\mathrm{SH})+2.41(\mathrm{RF})+1.41(\mathrm{AS}) \\
& +1.98(\mathrm{IN}), R^{2}=68 \%
\end{aligned}
$$

iii. 4-term equation, valid for total slopes $(n=31)$ :

$$
\begin{aligned}
\mathrm{PS} & =225.9+3.16(\mathrm{LF})+4.89(\mathrm{PO})+1.86(\mathrm{NS}) \\
& +1.81(\mathrm{WG}), \quad R^{2}=82 \%
\end{aligned}
$$

where SH is slope height, RF rockfall frequency, LF launching features, AS slope aspect, IN degree of interbedding, AP aperture of discontinuities, PO persistence and orientation of discontinuities, NS number of sets of discontinuities, and WG weathering condition of discontinuities.

Even though it is not as detailed as the overall measured score (based on 18 parameters for sedimentary rock masses), these equations can be used for a rapid, preliminary rating of the slope hazard (Santi et al., 2009).

In all three methods, the percentage of the decision sight distance (PDSD) category is employed. PDSD measures the percentage of reduction in the decision sight distance (DSD). For USA roads this percentage is obtained according to AASHTO (2011), whereas in Italy the Italian Road Rules must be used (Ministerial Decree 5/11/2001, no. 6972). According to these rules, PDSD is given by

$\mathrm{PDSD}=\frac{\mathrm{ASD}}{\mathrm{DSD}} \cdot 100 \%$,

where ASD is the actual sight distance $(\mathrm{km})$ and DSD represents the length of road $(\mathrm{km})$ a driver needs in order to make a complex or instantaneous decision.

In Italy, DSD is considered as the distance along a roadway within which a $15 \mathrm{~cm}$ high stationary object is continuously visible from $1.10 \mathrm{~m}$ above the road (i.e. the height of a driver's eye on the road). ASD in the two traffic directions should be evaluated because, normally, an object will be most obscured when it is located just beyond the sharpest part of a curve. Consequently, in the same road section depending on the two traffic directions, ASD can be greatly different.

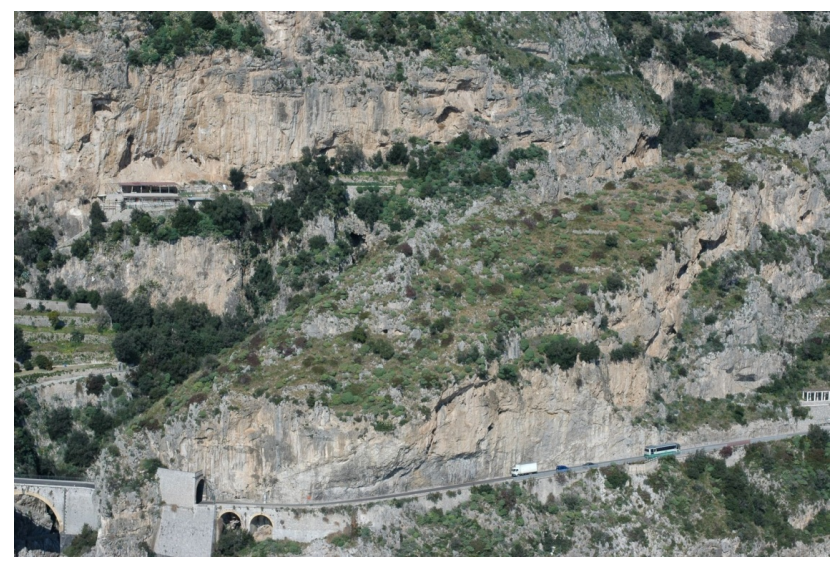

Fig. 2. The Conca dei Marini site with the vehicular flow on the Amalfitana road.

\section{The road stretch studied}

The road portion studied belongs to a very tortuous road path (Fig. 2) going along the coast (the Amalfitana no. 163 state road) that was built in the middle of the 19th century by the Bourbon Department of Bridges and Roads. As a result of its age and impossibility of a modern realignment (in order to preserve the environmental heritage of this area protected by UNESCO), the road is characterised by the following: (i) only one single lane going in each direction without an adequate hard shoulder, which does not leave enough space for the driver to swerve to avoid any fallen rocks; (ii) no ditches to retain any fallen rocks, allowing the material to spill out onto the road; and (iii) a high degree of road curvature resulting in a small PDSD. The width of the road is $7.0 \mathrm{~m}$, but it is not wide enough in most places to allow vehicles to overtake one another (especially buses and trucks) or vehicles travelling in opposite directions meeting up.

The road stretch, of $11.050 \mathrm{~km}$ in length (from $\mathrm{km} 23+$ 700 to $\mathrm{km} 34+750$ with increasing progressive kilometres towards Salerno) crossing several municipal territories, has been subdivided into 56 sections. These sections, with lengths varying between about 330 and $70 \mathrm{~m}$, were defined so as to have - as much as possible - homogeneous geological characteristics. Seventeen sections having a total length of about $3.6 \mathrm{~km}$ were rejected from further processing because slopes flanking the road are either not affected by potential rockfalls or are anthropized with buildings and high walls. By means of topographic maps and field measurements, ASD for the remaining 39 sections, in both directions, were calculated by the following (Ministerial Decree 5/11/2001, no. 6972):

$\mathrm{ASD}=2 \sqrt{2 R(b+c)}$,

where $R$ is the radius of the curvature of the road (measured by the topographical map), $b$ the distance between the driver's eye and the edge of the road curve, and $c$ the distance 
between a possible boulder placed on the lane and the edge of the road curve.

Where sight distances are more critical, due to the presence of obstacles or vegetation, $b$ values were measured using levelling rods. For the sake of simplicity, the supposed boulder position on the road was always assumed at $c=3.50 \mathrm{~m}$ from the edge of the curve, this distance being half of the road width. The posed speed limits (PSLs), as a function of the tortuous road path, are 50,40 and $30 \mathrm{kmh}^{-1}$. PDSD obtained using Eq. (5) for all sections, varies between $38 \%$ and $30 \%$, and it is always very limited.

An analysis of traffic data recorded in the spring/summer and the autumn/winter periods of 2003, and for different sunlight conditions (day and night), was performed by Cantarella and De Luca (2006). About $80 \%$ of the traffic is made up of cars and the remainder of tourist coaches and motorcycles. Considering the average daily traffic (ADT) data, during the two above-mentioned periods, there are not any notable differences and the traffic is almost constant. The vehicular flow due to commuting and business (very intense in the low season) during the spring/summer period is replaced by an equally intense tourism one.

In order to evaluate the average vehicle risk (AVR), ADT and PSL data were used according to the following formula (Pierson et al., 1990):

$\mathrm{AVR}=\frac{(\mathrm{ADT} \cdot \mathrm{SL} \cdot 100 \%)}{\mathrm{PSL}}$

where SL is the hazard zone length $(\mathrm{km})$.

AVR represents the spatial probability of occurrence of a vehicle in the rockfall road sector and varies as a function of the two road directions and seasons of the year. Along the road, AVR varies between $8.7 \%$ (in the winter period) and $66.4 \%$ (in the summer period).

\section{Field surveys and geological data}

The study area (Fig. 1) lies on the northern side of the Gulf of Salerno. This area belongs to the wider context of the Sorrento-Amalfi peninsula that, in turn, is a carbonatic horst which is transversal to the Southern Apennine chain, separating two tectonic depressions - the Campania Plain to the north and the Gulf of Salerno to the south (Bonardi et al., 2009). Major NE-SW-trending faults delimit the peninsula, which is also affected by several NW-SE transverse faults (partly strike-slip faults) creating secondary horstgraben structures. As a result of the heavy tectonic disturbance, outcropping rock masses are always extremely fractured (Fig. 3).

In order to detect geometrical and geological parameters needed for the application of selected QRSs, field surveys were carried out on slopes flanking the 39 road sections potentially affected by rockfalls. With reference to climate conditions (annual precipitations and freeze-thaw cycles) as well the water infiltration, references were made to

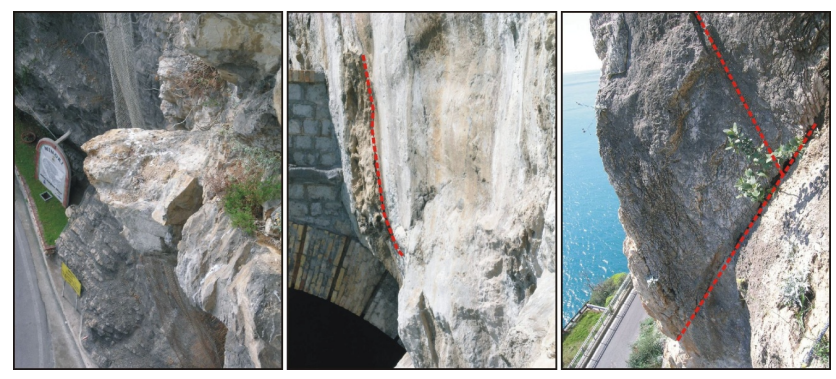

Fig. 3. Examples of unstable blocks impending over the studied road stretch.

Ducci and Tranfaglia (2008). For the study area (in the period 1951-1980), average values of the annual precipitation and temperature were $1350 \mathrm{~mm} \mathrm{yr}^{-1}$ and $15^{\circ} \mathrm{C}$, respectively, while the average infiltration rate is $450 \mathrm{~mm} \mathrm{yr}^{-1}$ (Ducci and Tranfaglia, 2008). In order to rate geomechanical features of discontinuities (such as joint orientations and spacing, rock-quality designation (RQD), apertures, shear strength of discontinuities and so on), needed for calculation of SMR index (coupled in mRHRS), about 40 perpendicular scan lines were carried out by experienced rock-climbing geologists. Due to the significantly more complex and laborious approach required in mRHRS with respect to the other two methods, only seven slopes at Conca dei Marini, Amalfi, and Maiori were studied.

Briefly, with reference to the main geometrical and geological characteristics of the slopes flanking the entire road stretch, the following features can be highlighted. Many slopes (about $46 \%$ ) have heights greater than $30 \mathrm{~m}$ with average slope angles varying between $80^{\circ}$ and $87^{\circ}$. Almost vertical slope profiles favour the free fall of boulders on the road, whereas in the remaining cases irregular rock faces, due to the presence of ridges or benches with lower slopes, cause launching and rebounding phenomena. On the slopes, the cross-bedded Jurassic limestones outcrop, on average dipping approximately $20^{\circ} \mathrm{W}-\mathrm{SW}$, and sometimes rock masses crop out dipping less than the slope or with horizontal strata. A heavy tectonic disturbance affects the carbonate rock masses favouring prismatic or slab block detachments along the strata. Three joint sets or more can be found corresponding to fractures striking parallel to the slopes or with mutually intersecting Apenninic (NW-SE) and antiApenninic (NE-SW) trends. Locally, a complex structural setting can be found due to several folds with eastwardverging axes. With reference to the joint characters, the joint spacing ranges between moderately wide to very wide. Except for bedding planes, displaying tight apertures, all other tectonic discontinuities are open and very open joints, almost all filled with pyroclastic and clayey materials from run-off. Cavities and very open joints due to the chemical dissolution of limestones in several sites are present, and karst dissolution is an active geomorphological process weakening over 
time the intact rock portions (rock bridges) separating the adjacent rock walls with open discontinuities.

\section{Rockfall events and return periods}

High cuts and natural slopes give rise to falls, planar or wedge slides and, more rarely, topples mainly due to the unfavourable layout of the joints, geomorphology, climate, and vegetation (joint enlargement caused by the roots of the plants). With reference to the entire road path of the Amalfitana from Positano to Cetara, Ferlisi et al. (2012) prepared a rockfall database using different documentary sources that covers a time span from 1853 to 1999 . Rockfalls were classified on the basis of the magnitude (boulder volume) deposed on the road. A total of 82 rockfalls were recorded. The rockfall inventory was enlarged using new data by ANAS (the national company which owns the road) related to the time span from 2000 to 2008, and IFFI Catalogue (Progetto IFFI, 2010) spanning from 1969 to 1998. In such a way, a database reporting the progressive kilometres, dates and municipalities in which falls happened was prepared covering a time span from 1969 to 2008 (Table 1). A total of 33 events were recorded with a maximum rockfall density affecting road sections crossing the territories of Conca dei Marini and Amalfi. Due to the non-recording of small rockfall volumes by ANAS, the catalogue is incomplete. Rockfalls mainly occur in autumn/winter depending on high-intensity and shortduration rainfalls usually occurring during the months of October and November. Secondary falls of already detached boulders that are no longer supported by vegetation often result from summer wildfires.

According to Corominas and Moya (2008), the rockfall frequency was expressed as relative frequency $\left(f_{\mathrm{r}}\right)$ (i.e. the number of rockfalls reaching the infrastructure per unit length and per year). Reliable data can be referred to only for sections crossing the territory of Conca dei Marini and Amalfi for which values of $f_{\mathrm{r}}$ of about 0.14 and 0.13 events $\mathrm{yr}^{-1} \mathrm{~km}^{-1}$ were calculated. An explanation for these low $f_{\mathrm{r}}$ values is the presence of protection measures (such as barriers or wire meshes) on a lot of slopes hanging over the road with more put in place during the 1980s and 1990s. For safety reasons, in QRS calculations these protection measures were not taken into account. Consequently, along protected road stretches the hazard could be overestimated.

For road sections crossing the territory of Conca dei Marini, an attempt was made so as to derive rockfall return periods - for assigned volume classes - using the landslide magnitude-frequency curves (MFCs). According to Hungr et al. (1999), Dussauge et al. (2003) and Malamud et al. (2004), the MFC for rockfalls can be described by a power law in the following form:

$\log N(V)=N_{0}+b \cdot \log V$,
Table 1. Progressive distances where rockfalls occurred.

\begin{tabular}{|c|c|c|}
\hline $\begin{array}{l}\text { Progressive } \\
\text { kilometres }\end{array}$ & Date & Municipality \\
\hline $23+700$ & - & Furore \\
\hline $24+000$ & April 2007 & Furore \\
\hline $24+100$ & January 2001 & Conca dei Marini \\
\hline $24+200$ & March 2008 & Conca dei Marini \\
\hline $24+600$ & January 2001 & Conca dei Marini \\
\hline $25+000$ & April 2002 & Conca dei Marini \\
\hline $25+100$ & - & Conca dei Marini \\
\hline $25+300$ & - & Conca dei Marini \\
\hline $25+400$ & - & Conca dei Marini \\
\hline $25+500$ & - & Conca dei Marini \\
\hline $26+300$ & - & Conca dei Marini \\
\hline $26+320$ & April 2002 & Conca dei Marini \\
\hline $26+350$ & - & Conca dei Marini \\
\hline $26+400$ & September 1996 & Conca dei Marini \\
\hline $26+420$ & - & Conca dei Marini \\
\hline $26+650$ & December 2002 & Conca dei Marini \\
\hline $26+700$ & May 2000 & Conca dei Marini \\
\hline $28+100$ & - & Amalfi \\
\hline- & September 1997 & Amalfi \\
\hline $29+000$ & - & Amalfi \\
\hline $29+200$ & December 2004 & Amalfi \\
\hline $29+300$ & - & Amalfi \\
\hline $29+400$ & November 1997 & Amalfi \\
\hline $29+450$ & November 1997 & Amalfi \\
\hline $29+650$ & January 1994 & Amalfi \\
\hline $33+000$ & November 1997 & Ravello \\
\hline $33+200$ & November 1997 & Minori \\
\hline $34+000$ & - & Minori \\
\hline $34+500$ & October 2003 & Minori \\
\hline $34+580$ & August 1998 & Minori \\
\hline $34+600$ & November 1994 & Maiori \\
\hline $34+700$ & January 1969 & Maiori \\
\hline $34+750$ & September 2006 & Maiori \\
\hline
\end{tabular}

where $N(V)$ is the cumulative annual frequency of rockfall events exceeding a given volume class $j, N_{0}$ the annual rockfall frequency, and $b$ the power law exponent.

$N(V)$ in a given volume class $j$ (i.e. $N_{j}$ ) can be calculated according to the approach by Hungr et al. (1999). In the case where site-specific magnitude values are missing, Agliardi et al. (2009) suggested the use of a value of -0.41 for the exponent $b$ derived from the literature (i.e. the value for carbonate rocks proposed by Dussauge et al., 2003). This value usually varies within a quite narrow range, i.e. $-0.7<b<-0.4$ (Hungr et al., 1999; Dussauge et al., 2003; Picarelli et al., 2005). With reference to the rockfall inventory, and the $f_{\mathrm{r}}$ value of about 0.14 events $\mathrm{yr}^{-1} \mathrm{~km}^{-1}$, return periods varying between about 11.7 and $77 \mathrm{yr}$ (for the rockfall magnitude interval $1 \div 100 \mathrm{~m}^{3}$ ) were calculated (Table 2). Caution should be taken when using these data due to uncertainties springing from the lack of a substantially complete catalogue. 
Table 2. Rockfall volume classes, expected frequencies, and return periods according to the adopted magnitude-frequency curve (MFC).

\begin{tabular}{cccc}
\hline $\begin{array}{c}\text { Rockfall } \\
\text { magnitude } \\
\text { class } \\
\left(\mathrm{m}^{3}\right)\end{array}$ & $\begin{array}{c}\text { Annual } \\
\text { cumulative } \\
\text { frequency } \\
\left(f_{i}\right)\end{array}$ & $\begin{array}{c}\text { Annual } \\
\text { incremental } \\
\text { frequency } \\
\left(f_{\mathrm{h}}\right)\end{array}$ & $\begin{array}{c}\text { Return } \\
\text { period } \\
(\mathrm{yr})\end{array}$ \\
\hline 0.1 & 0.14 & - & - \\
1 & 0.054 & 0.086 & 11.69 \\
10 & 0.021 & 0.033 & 30.05 \\
100 & 0.008 & 0.013 & 77.24 \\
1000 & 0.003 & 0.005 & 195.5 \\
\hline
\end{tabular}

\section{Results and comparison between the employed methods}

\subsection{RHRS results}

The total rating was calculated for each of the 39 sections in both traffic directions (towards Furore and Maiori) and in two periods per year (spring/summer and autumn/winter) (Fig. 4). No appreciable difference was found among scores with reference to the above-mentioned conditions because, due to a very tortuous road path with small radii of curvatures, PDSD is always very limited. With reference to AVR there are no great differences among the sections because, during the year, the daily traffic is almost constant. Along the road there are no ditches to retain any fallen rocks; ditch catchment, PDSD, and AVR are the factors that affect the consequence score. Among sections, differences in the hazard score are mainly due to the slope height, structural condition + friction, block size and rockfall history categories. These are the parameters that undergo most changes.

It is worth observing that, in $74 \%$ of the cases, the sum of scores of consequence factors is higher than those coming from hazard factors (Fig. 4). In particular this is true for sections nos. 21, 30, 44, 45 and 50 with a low hazard score (about 100), whereas the consequence score attains a double value compared to the first one (about 220, on average). This occurrence highlights that the rockfall risk is mainly due to the lack of ditches, very limited PDSD values and a small roadway width. As shown by low relative frequency $\left(f_{\mathrm{r}}\right)$ values, the hazard due to these rockfalls is a minor factor.

\section{2 mRHRS results}

Due to the significantly more complex and laborious approach required by mRHRS, compared to the original RHRS, only five road sections at Conca dei Marini, one section at Amalfi, and one section at Maiori were studied. These sections were chosen because they have recognizable boundaries on the map scale $(1: 5000)$ and their overall homogeneity is a function of their relief type, geomorphology and ge-

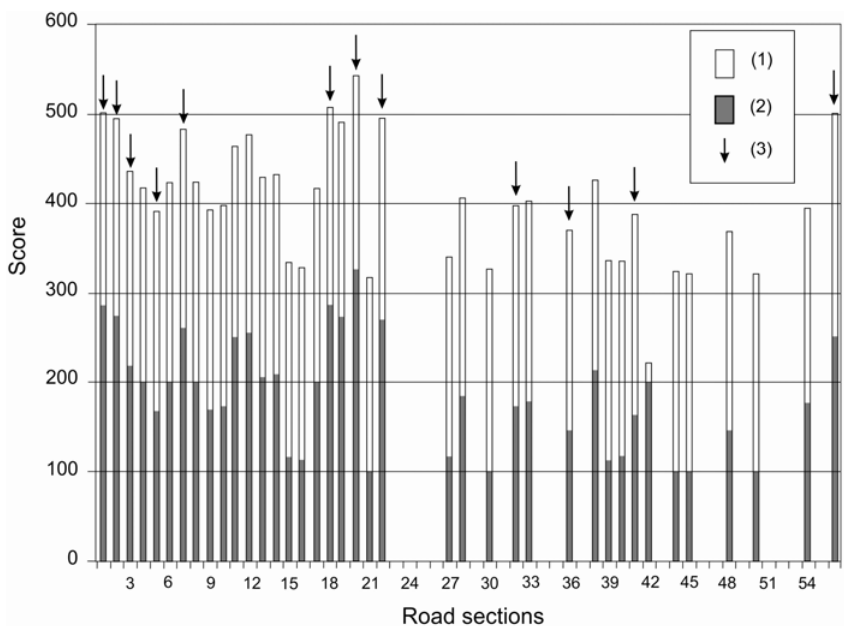

Fig. 4. The rockfall risk rating for the traffic direction towards Furore and for the spring/summer period, recorded for the 33 road sections studied by means of the RHRS. (1) Consequence score; (2) hazard score; and (3) road section affected by rockfalls.

ological structure. A total length of about $890 \mathrm{~m}$ of the road path was characterised.

On the basis of the geostructural features of discontinuities (joint orientation, spacing, RQD, joint condition and groundwater) and uniaxial compression strength values, a common rating regarding the basic rock mass rating (RMR) by $\mathrm{Bi}$ eniawski (1989) has been calculated for all road sections $\left(\mathrm{RMR}_{\mathrm{b}}=65\right)$, given the homogeneity of the investigated rock masses. The SMR index (Romana, 1985), varying between 42 and 89 , identifies instability classes ranging from the second ("stable slopes") to the third class ("partially stable slopes") with a clear prevalence of the second class cropping out in all three studied sites (Fig. 5). Similarly to what has already been evaluated by means of RHRS, this occurrence testifies a low rockfall hazard. Furthermore, according to Palmström (1996) and ISRM (1978), block volumes ( $\left.V_{\mathrm{b}}\right)$ vary between 10 and $100 \mathrm{dm}^{3}$. Even though poorer geomechanical properties and consequent slope stability conditions were detected at Conca dei Marini and Maiori, these sites do not show a higher difference in the total hazard score, compared to Amalfi. Here (section no. 38), higher scores of the slope height category greatly contribute to raise the hazard.

\subsection{CRHRS results}

In order to apply this method, new parameters that were not already used in the previous methods have been surveyed and appropriately rated. These parameters are as follows: the average slope angle (AN), launching features (LF), freezethaw cycles (FT) and, slope aspects (AS), as well as parameters regarding geological characteristics, such as the degree of undercutting (UN), jar slake (JS) and the degree of interbedding (IN). Once all the CRHRS factors are rated, the average contribution (in \%) on the total final rating, for each 

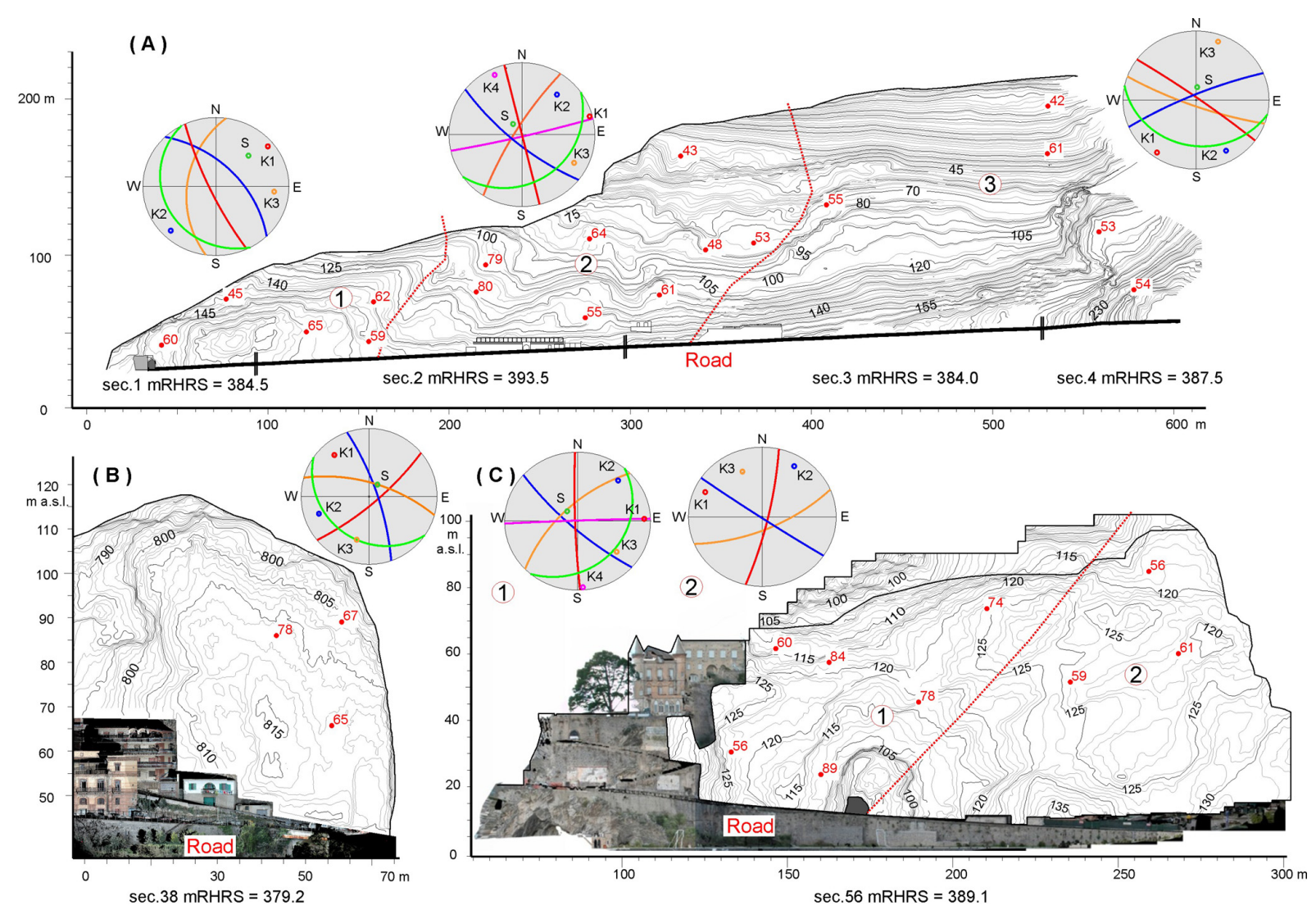

Fig. 5. mRHRS values characterising some of road sections and cyclographic projections of joint sets affecting homogeneous zones of rock masses. Key: (A) Conca dei Marini; (B) Amalfi; (C) Maiori; S - poles of bedding planes; K1 ... Kn - poles of tectonic joint sets. The red dots show the location of the geomechanical stations and related SMR values.

score category, was calculated (Fig. 6). Ditch catchment, annual precipitation and PDSD factors have the highest percentage contribution, whereas the slope characters, geological factors, as well as launching features reach percentages varying between $10 \%$ and $4 \%$. All other factors attain percentages smaller than $1.5 \%$ (Fig. 6). In conclusion, a small contribution to overall rockfall risk is supplied by the following categories: rockfall frequency, annual freeze-thaw cycles, seepage, degree of undercutting, jar slake, degree of interbedding, block size, friction, AVR, and the number of accidents.

In order to predict the total hazard score (PS), using fewer parameters than the 18 contained in the CRHRS, the equations developed by Santi et al. (2009) were used. Linear regressions were obtained correlating the actual measured CRHRS score (based on 18 parameters recorded in the field) with the score predicted from Eqs. (2), (3), and (4). The best fits were obtained using the linear least square regression within a $95 \%$ confidence interval - on the above-mentioned predictive equations, which are based on more independent variables (Fig. 7). The strength of the linear association between variables was judged on the basis of the calculated coefficient of determination $R^{2}$ (ranging between $69 \%$ and

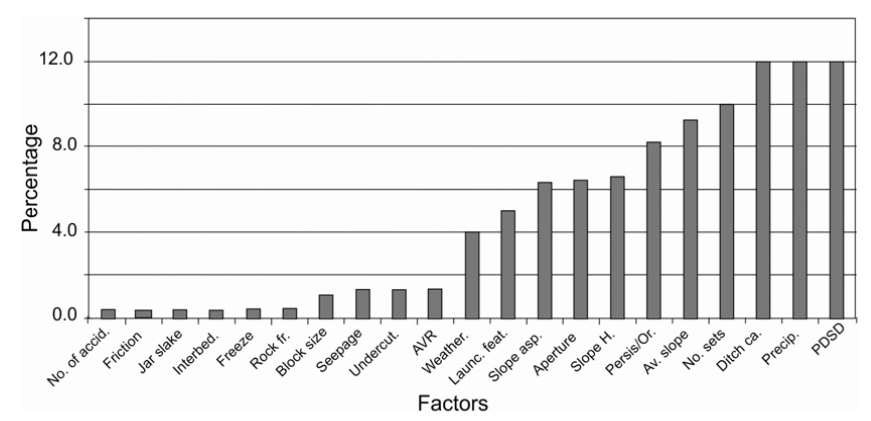

Fig. 6. Percentage contribution to the total final rating of the categories employed in the CRHRS.

$87 \%$ ). It is worth observing that, in order to predict PS values, five hazard variables ( $\mathrm{SH}, \mathrm{LF}, \mathrm{AS}, \mathrm{AP}$, and WG) were used - out of a total of 10 that appear in Eqs. (2) and (4) having a higher percentage contribution to the measured 18term score. On the contrary, in the 4-term Eq. (3), two hazard variables (RF and IN) are characterised by low percentage contributions (smaller than $1.5 \%$ ). Consequently, this equation seems to be less suitable for predicting reliable PS values. This occurrence is also confirmed by the higher values 

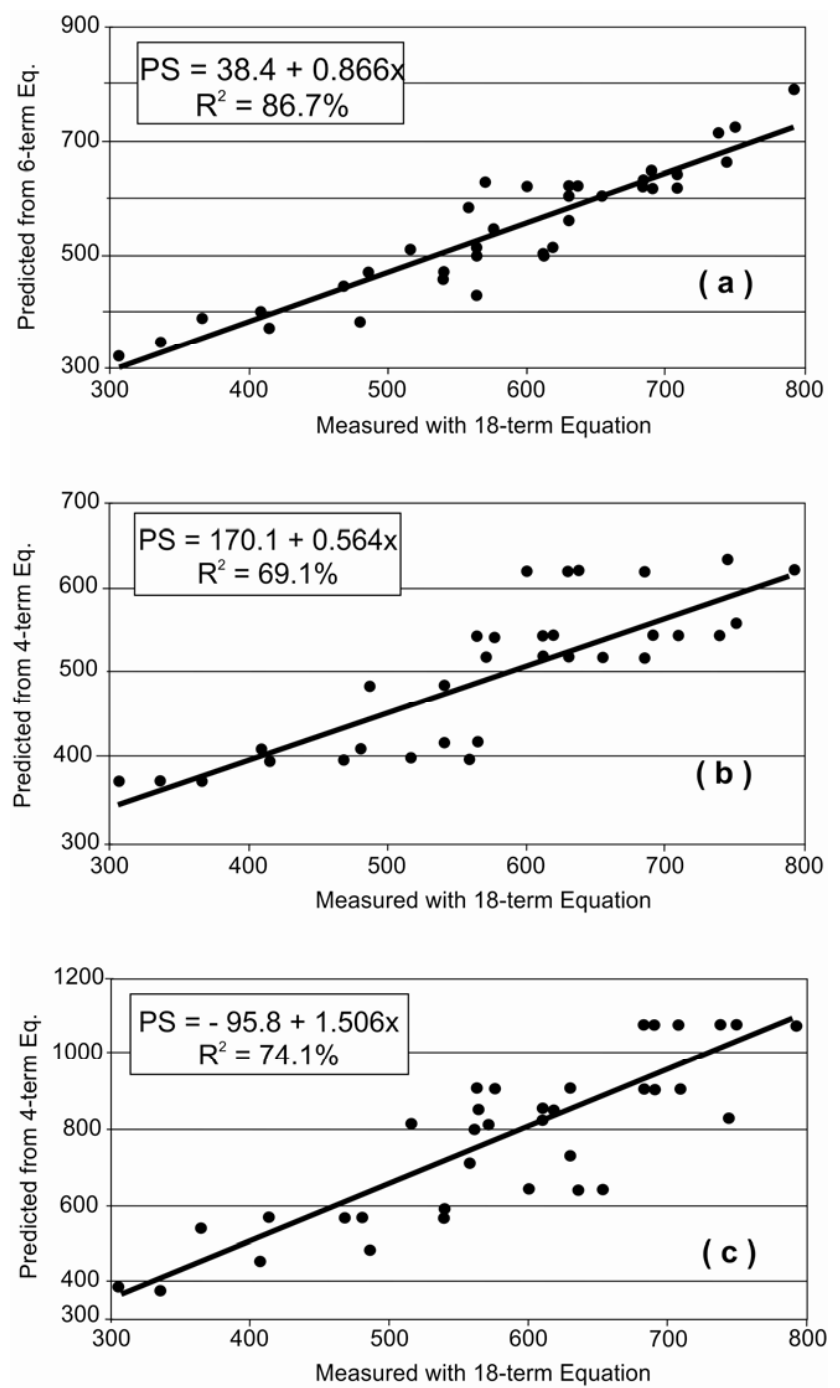

Fig. 7. Linear regressions obtained using Eqs. (2), (3) and (4) by Santi et al. (2009). The x-axis plots the actual measured CRHRS score based on 18 parameters recorded in the field. The y-axis plots scores attained from the 6-term equation valid for cut slopes (a), 4term equation valid for cut slopes (b), and 4-term equation valid for total slopes (c).

of the $R^{2}$ obtained linking PS values calculated with Eqs. (2) and (4) to the measured 18-term score (Fig. 7).

Total scores calculated by means of RHRS and CRHRS vary between $317 \div 543$ and $400 \div 879$, respectively. As a greater number of factors (18) must be rated by means of CRHRS, final ratings are higher than those obtained with the RHRS method (10 parameters). Nevertheless, as is evident from their respective normalized coefficients of variation (CV), the two intervals of values are characterised by a very low relative variability (Table 3 ). $\mathrm{CV}$ is given by

$\mathrm{CV}=\frac{\sigma}{\mu \sqrt{n-1}} \quad 0 \leq \mathrm{CV} \leq 1$,
Table 3. Main statistical data obtained with the employed methods. Interval values refer to the spring/summer period and in the direction towards Furore. Arithmetic mean $(\mu)$; standard deviation $(\sigma)$; normalized coefficient of variation $(\mathrm{CV})$.

\begin{tabular}{lllll}
\hline Method & Interval values & $\mu$ & $\sigma$ & CV \\
\hline RHRS & $317 \div 543$ & 410 & 61.269 & 0.024 \\
CRHRS & $339 \div 879$ & 676 & 120.745 & 0.028 \\
\hline
\end{tabular}

where $\sigma$ is the standard deviation and $\mu$ the arithmetic mean of the population ( $n$ data).

A good correlation was also found between final scores, which shows an increasing linear trend of CRHRS values as a function of the RHRS increase. The found equation is

CRHRS $=17.96+1.61$ RHRS $\quad r=0.82$,

where $r$ is Pearson's correlation coefficient.

At last, in order to perform an effective comparison between the systems to be achieved, total scores were appropriately standardized. Each value is expressed as a percentage ratio on the maximum value so that the highest risk index will be 1 and so on, until the minimum value. For each system three classes, which limit values identifying a high, medium and low risk respectively, have been fixed up (Fig. 8). Threshold limit values between classes were identified taking into account rockfalls that occurred in each road section. Although $76 \%$ of rockfalls affected sections with a high risk level, the remaining percentage involved sections with a medium risk. This is not surprising because it is possible that, for some sections falling within this medium risk, the hazard score is comparable to that characterising sections affected, however, by a greater consequence score.

With reference to the mRHRS method, due to not many available data (only 7), it is impossible to perform a reliable statistical analysis. Consequently, only a general qualitative agreement between the ratings of hazard factors calculated by means of the three selected methods can be seen.

\section{$7 \quad$ Discussion and conclusions}

In the international literature there are no investigations concerning the main differences and similarities among the above-mentioned methods. Consequently, in order to compare results an attempt was performed on a road flanked by rock slopes characterised by complex geostructural and geomechanical layouts.

As far as the results for the RHRS are concerned, the rating calculated for each of the 39 sections is based on not many geological factors, qualitatively described and, therefore, are not reliable enough. Also the climate, presence of water on the slope, and rockfall history categories are too subjectively evaluated. The results proved that a high risk level, affecting 


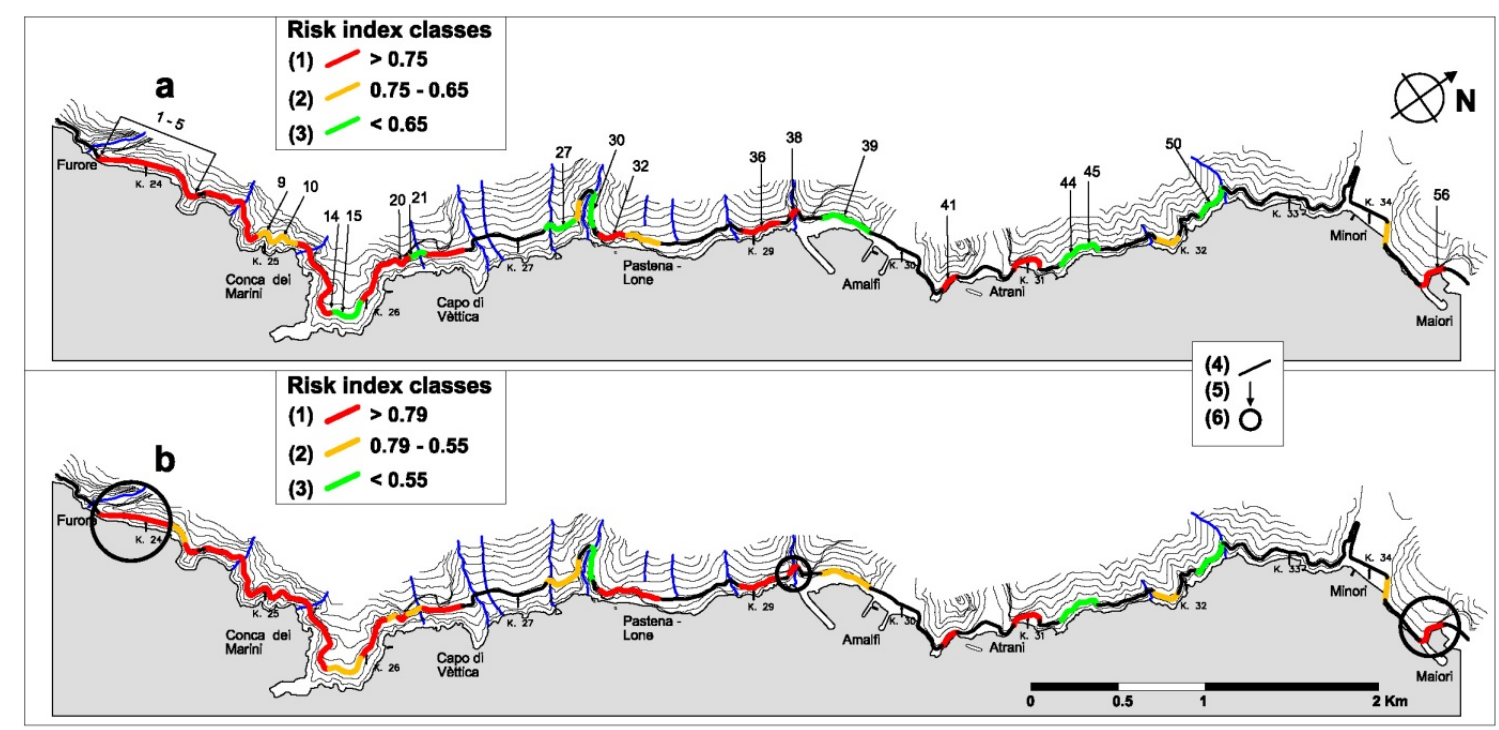

Fig. 8. Comparison between rockfall risk classes evaluated, for the entire road stretch, by means of the RHRS (a) and CRHRS (b). (1) High rockfall risk; (2) medium rockfall risk; (3) low rockfall risk; (4) road section unaffected by potential rockfalls; (5) road section quoted in the text; and (6) road section studied by means of the mRHRS.

some road sections, is mainly due to the lack of ditches, low PDSD values and a small roadway width, whereas a subordinate factor is the hazard caused by rockfalls. This result is in general agreement with low relative frequency $\left(f_{\mathrm{r}}\right)$ values calculated for the road sections which display more reliable rockfall data (such as at Conca dei Marini and Amalfi). As far as the results of the mRHRS are concerned, it has been possible to avoid subjective ratings for the geological characteristics, by means of applying the SMR index. However, in order to apply Romana's SMR many scan lines and field measurements carried out by experienced rock-climbing geologists were necessary. The use of the SMR index may provide a better description of the rock slope stability, but makes the method significantly more complex than the original RHRS and may require more training and experience. This approach is notoriously laborious and cannot be applied along many kilometres of the road. Although it is impossible to statistically compare mRHRS final ratings with those supplied by the other two methods (due to the few rated sections), a general qualitative agreement between the data available can be seen. If we compare only the ratings of hazard factors, this occurrence can be clearly seen. In fact, the hazard parameters may vary considerably case by case, whereas very often the consequence factors have similar scores.

With reference to the CRHRS, smaller differences can be observed between the final risk of the rated sections. This occurrence is probably due to the presence of more numerous categories (ditch catchment, precipitations, freeze-thaw cycles, seepage/water, jar slake, degree of interbedding, and the number of accidents) with similar scores with respect to the other two methods. Because a greater number of factors are analysed and then rated, final ratings are higher than those obtained using the other two methods. Consequently, in or- der to compare the employed methods, it was necessary to standardize them. With reference to the rockfall hazard calculated using the equations by Santi et al. (2009), it is not necessary to rate all 18 parameters regarding the outcropping sedimentary rock masses. The study showed that even though the four parameters in Eq. (3) are more easily detectable with field surveys or maps (the factors $\mathrm{SH}, \mathrm{RF}$, and AS can be directly measured and then scored, whereas only IN requires a subjective evaluation), higher $R^{2}$ values are obtained correlating the values of PS - calculated with Eqs. (2) and (4) - to the measured 18-term score. A higher effectiveness of these equations can be assumed.

The adopted methods are "first-level" (RHRS and CRHRS) and "intermediate" (mRHRS) characterisation systems useful for subsequent detailed geomechanical analyses in well-located high-hazard areas (Fell et al., 2008). With reference to needed equipment and expert knowledge, ease of use, and flexibility of the systems, a comparison is proposed in Table 4. If needed input data along many kilometres of road are defective, it is preferable to use CRHRS as a firstlevel method. In order to predict the rockfall hazard, it is also possible to perform reliable statistical analyses. On the contrary, if more suitable and numerous geological, traffic, geomechanical and topographical data are available, mRHRS as an intermediate characterisation method might be used.

Finally, it should be kept in mind that results supplied by the above-mentioned methods require continuous updating. This happens not only when a better assessment of any components can modify the calculated risk level (e.g. changes in traffic intensity over time) but also when either stabilization or protective measures have been implemented (Ferlisi et al., 2012; Corominas et al., 2008). 
Table 4. General comparison between criteria and concise overall assessment.

\begin{tabular}{|c|c|c|c|}
\hline Criteria & RHRS & mRHRS & CRHRS \\
\hline $\begin{array}{l}\text { Needed data } \\
\text { and equipment }\end{array}$ & $\begin{array}{l}\text { Road geometry, topographic maps, } \\
\text { traffic data, qualitative geologic } \\
\text { surveys, rockfall history, climate } \\
\text { conditions (at small/medium scale), } \\
\text { levelling rods. }\end{array}$ & $\begin{array}{l}\text { Road geometry, traffic data, } \\
\text { geostructural and geomechanical data, } \\
\text { rockfall database, climate conditions } \\
\text { (at large scale), terrestrial photogrammetry, } \\
\text { levelling rods. }\end{array}$ & $\begin{array}{l}\text { Road geometry, topographic maps, } \\
\text { orthophotos, traffic data, qualitative } \\
\text { and quantitative geologic surveys, } \\
\text { rockfall history, climate conditions } \\
\text { (at small/medium scale), levelling rods. }\end{array}$ \\
\hline $\begin{array}{l}\text { Needed expert } \\
\text { knowledge }\end{array}$ & $\begin{array}{l}\text { Adequate (geometer, } \\
\text { undergraduate studies } \\
\text { in geology or } \\
\text { environmental engineer). }\end{array}$ & $\begin{array}{l}\text { In-depth (graduate } \\
\text { studies in geology or } \\
\text { engineering geology). }\end{array}$ & $\begin{array}{l}\text { Good (graduate } \\
\text { studies in geology or } \\
\text { engineering geology). }\end{array}$ \\
\hline Ease of use & $\begin{array}{l}\text { Easy but subjective and } \\
\text { based on not very geological } \\
\text { factors, qualitatively described. } \\
\text { It applies along many } \\
\text { kilometres of roads. }\end{array}$ & $\begin{array}{l}\text { Complex but objective. } \\
\text { It applies to limited road stretches. }\end{array}$ & $\begin{array}{l}\text { Fair but sometimes subjective. } \\
\text { Several topographical and } \\
\text { geological data are required. } \\
\text { It applies along various } \\
\text { kilometres of roads. }\end{array}$ \\
\hline $\begin{array}{l}\text { Flexibility of } \\
\text { the system }\end{array}$ & $\begin{array}{l}\text { Very flexible } \\
\text { (it applies to all } \\
\text { lithologic settings). }\end{array}$ & $\begin{array}{l}\text { Not very flexible } \\
\text { (mainly it applies to } \\
\text { sedimentary rock masses with } \\
\text { clear discontinuity patterns). }\end{array}$ & $\begin{array}{l}\text { Flexible (it applies to } \\
\text { sedimentary, block-in-matrix } \\
\text { and crystalline rock masses). }\end{array}$ \\
\hline Overall assessment & $\begin{array}{l}\text { Unreliable } \\
\text { (due to its subjectivity). }\end{array}$ & Very reliable but laborious. & $\begin{array}{l}\text { Reliable. It is possible to } \\
\text { perform statistical } \\
\text { analyses in order to } \\
\text { predict the rockfall hazard. }\end{array}$ \\
\hline
\end{tabular}

Acknowledgements. The authors are grateful to D. Calcaterra, B. Merz and three referees for their valuable comments and suggestions that improved this paper. The authors would also like to thank the Regional Agency "Autorità di Bacino Destra Sele" and ANAS "Ente Nazionale per le Strade", who provided geomechanical, traffic, and landslide data. This work was carried out with a financial contribution from the University of Naples "Federico II", under the guidance of P. Budetta.

Edited by: B. Merz

Reviewed by: L. Pantelidis and two anonymous referees

\section{References}

AASHTO (American Association of State and Highway Transportation Officials): A Policy on Geometric Design of Highways and Streets (The Green Book), AASHTO, Washington, 906 pp., 2011.

Agliardi, F., Crosta, G. B., and Frattini, P.: Integrating rockfall risk assessment and countermeasure design by 3D modelling techniques, Nat. Hazards Earth Syst. Sci., 9, 1059-1073, doi:10.5194/nhess-9-1059-2009, 2009.

Bateman, V.: Development of a database to manage rockfall hazard: The Tennessee rockfall hazard database, in: Proc. 82nd annual meeting of Transportation Research Board, Washington DC, 97103, doi:10.3141/1821-12, 2003.

Bieniawski, Z. T.: Engineering Rock Mass Classifications, John Wiley \& Sons, New York, 251 pp., 1989.

Bonardi, G., Ciarcia, S., Di Nocera, S., Matano, F., Sgrosso, I., and Torre, M.: Carta delle principali unità cinematiche dell' Appennino meridionale - Nota illustrative, It. J. of Geosci., 128, 47-60, doi:10.3301/IJG.2009.128.1.47, 2009 (in Italian).

Budetta, P.: Assessment of rockfall risk along roads, Nat. Hazards Earth Syst. Sci., 4, 71-81, doi:10.5194/nhess-4-71-2004, 2004.

Budetta, P., De Riso, R., and Santo, A.: Landslide hazard and risk along the campanian roads (Italy), in: Proc. Int. Congr. "Géoline", Lyon, France, 1-13, 2005.

Bunce, C. M., Cruden, D. M., and Morgenstern, N. R.: Assessment of the hazard from rockfall on a highway, Can. Geotech. J., 34, 344-356, doi:10.1139/t97-009, 1997.

Cantarella, G. E. and De Luca, S.: Studio della mobilità in Costiera Amalfitana per un sistema integrato di trasporto collettivo, Research report, Department of Civil Engineering, University of Salerno, Italy, 105 pp., 2006 (in Italian).

Corominas, J. and Moya, J.: A review of assessing landslide frequency for hazard zoning purposes, Eng. Geol. 102, 193-213, doi:10.1016/j.enggeo.2008.03.018, 2008.

Drumm, E. C., Mauldon, M., Dunne, W., Bateman, V. C., and McCarter, B.: Rockfall Management System for Tennessee: Final Report - Phase II, Tennessee Department of Transportation, Nashville, available at: www.tdot.state.tn.us/longrange/reports/ res1189.pdf, last access: 20 June 2012, 2005.

Ducci, D. and Tranfaglia, G.: The effect of climate change on the hydrogeological resources in Campania region (Italy), in: Groundwater and climatic changes, edited by: Dragoni, W., Geological Society, London, Special Publications, 288, 25-38, doi:10.1144/SP288.3, 2008.

Dussauge, C., Grasso, J. R., and Helmstetter, A.: Statistical analysis of rockfall volume distributions: implications for rockfall dynamics, J. Geophys. Res., 108, 2286, doi:10.1029/2001JB000650, 2003. 
Fell, R., Corominas, J., Bonnard, C., Cascini, L., Leroi, E., and Savage, W. Z.: Guidelines for landslide susceptibility, hazard and risk zoning for land-use planning, Commentary, Eng. Geol., 102, 99-111, doi:10.1016/j.enggeo.2008.03.009, 2008.

Ferlisi, S., Cascini, L., Corominas, J., and Matano, F.: Rockfall risk assessment to persons travelling in vehicles along a road: the case study of the Amalfi coastal road (Southern Italy), Nat. Hazards, 62, 691-721, doi:10.1007/s11069-012-0102-z, 2012.

Ferrero, A. M., Migliazza, M., Roncella, R., and Rabbi, E.: Rock slopes risk assessment based on advanced geostructural survey techniques, Landslides, 8, 221-231, doi:10.1007/s10346-0100246-4, 2011.

Franklin, J. A. and Senior, S. A.: The Ontario rockfall hazard rating system, in: Proc. Int. Conf. on Eng. Geol. and the Env., Balkema, Rotterdam, 1, 647-656, 1997.

Hack, R.: An evaluation of slope stability classification. Keynote Lecture, in: Proc. ISRM "Eurock 2002", edited by: Dinis da Gama, C. and Ribeira e Sousa, L., Sociedade Portuguesa de Geotecnia, Lisboa, Portugal, 3-32, 2002.

Hungr, O., Evans, S. G., and Hazzard, J.: Magnitude and frequency of rockfalls and rock slides along the main transportation corridors of southwestern British Columbia, Can. Geotech. J., 36, 224-238, doi:10.1139/t98-106, 1999.

ISRM (International Society of Rock Mechanics): Suggested methods for the quantitative description of discontinuities in rock masses, Int. J. Rock Mech. Min., 15, 319-368, 1978.

Lato, M. J., Diederichs, M. S., Hutchinson, D. J., and Harrap, R.: Evaluating roadside rockmasses for rockfall hazards using LiDAR data: optimizing data collection and processing protocols, Nat. Hazards., 60, 831-864, doi:10.1007/s11069-011-9872y, 2012 .

Liang, R., Geiger, G., Beach, K., and Pensomboon, G.: Landslide hazard rating system in Ohio DOT, in: Proc. of GeoCongress 2006 "GIS based site characterization and geohazard analysis", ASCE Conf. Proc., 245-269, doi:10.1061/40803(187)124, 2006.

Malamud, B. D., Turcotte. D. L., Guzzetti, F., and Reichenbach, P.: Landslide inventories and their statistical properties, Earth Surf. Proc. Land., 29, 687-711, 2004.

Mekni, M., Sahli, N., and Moulin., B.: A geosimulation approach involving spatially-aware agents a case study on the identification of risky areas for trains, in: Symp. Agent-Directed Simulation "ADS '08", Part of the 2008 Spring Simulation Multiconference (SpringSim'08), 39-44, 2008.

Mignelli, C., Lo Russo, S., and Peila, D.: ROckfall risk MAnagement assessment: the RO.MA. approach, Nat. Hazards, 62, 1109-1123, doi:10.1007/s11069-012-0137-1, 1012.

Ministerial Decree 5/11/2001, no. 6972: Norme funzionali e geometriche per la costruzione delle strade, Ministero delle Infrastrutture e dei Trasport, Gazzetta Ufficiale del 04/01/2002 n. 3, 90 pp., 2002 (in Italian).

Pack, R. T., Farnsworth, C. B., and Leonard, B. D.: Development of a rockfall hazard rating system for the State of Utah, in: Proc. of the First North American Landslide Conference, Vail, Colorado, 134-145, 2007.

Palmström, A.: The rock mass index (RMI) applied in rock mechanics and rock engineering, Joumal of Rock Mechanics and Tunnelling Technology, 11, 1-4, 1996.
Pantelidis, L.: Rock slope stability assessment through rock mass classification systems, Int. J. Rock Mech. Min., 46, 315-325, doi:10.1016/j.ijrmms.2008.06.003, 2009.

Pantelidis, L.: A critical review of highway slope instability risk assessment systems, B. Eng. Geol. Environ., 70, 395-400, doi:10.1007/s10064-010-0328-5, 2011.

Picarelli, L., Oboni, F., Evans, S. G., Mostyn, G., and Fell, R.: Hazard characterization and quantification, in: Proc. Landslide Risk Management, edited by: Hung, O., Fell, R., Couture, R., and Eberhardt, E., Taylor and Francis Group, London, 27-61, ISBN: 041538 043X, 2005.

Pierson, L. A. and Van Vickle, R.: Rockfall Hazard Rating System Partecipants' manual, Federal Highway Administration, US Department of Transportation, Report FHWA-SA-93-057, 104 pp. 1993.

Pierson, L. A., Davis, S. A., and Van Vickle, R.: Rockfall hazard rating system implementation manual. Report FHWA-OR-EG-9001. Federal Highway Administration, US Department of Transportation, 80 pp., 1990.

Pierson, L. A., Beckstrand, D. L., and Black, B. A.: Rockfall Hazard Classification and Mitigation System. Report FHWA/MT-05011/8176, State of Montana Department of Transportation Research Programs, 277 pp., available at: http://www.mdt.mt.gov/ research/projects/geotech/rockfall.shtml, last access: 12 January 2012, 2005.

Progetto IFFI: Inventario dei fenomeni franosi in Italia, available at: http://www.isprambiente.gov.it/it/progetti/ iffi-inventario-dei-fenomeni-franosi-in-italia, last access: 28 May 2013, 2010 (in Italian).

Romana, M.: New adjustment ratings for application of Bieniawski classification to slopes, in: Proc. Int. Symp. on "The role of rock mechanics”, ISRM, Zacatecas, Mexico, 49-53, 1985.

Romana, M.: Practice of SMR classification for slope appraisal, in: Proc. 5th Int. Symp. on Landslides, Balkema, Rotterdam, 12271229, 1988.

Romana, M.: SMR Classification, in: Proc. 7th Int. Congr. on Rock Mech., Balkema, Rotterdam, 955-960, 1991.

Rose, B. T.: Tennessee Rockfall Management System, Dissertation submitted to the faculty of Virginia Polytechnic Institute and State University in partial fulfilment of the requirements for the degree of Doctor of Philosophy in Civil Engineering, 100 pp., available at: http://scholar.lib.vt.edu/theses/available/ etd-10132005-133738/, last access: 29 May 2013, 2005.

Russell, C. P., Santi, P. M., and Higgins, J. D.: Modification and statistical analysis of the Colorado Rockfall Hazard Rating System, Report CDOT-2008-7, Colorado Department of Transportation DTD Applied Research and Innovation Branch, 137 pp., available at: http://www.coloradodot.info/programs/ research/pdfs/2008/crhrs.pdf, last access: 20 June 2012, 2008.

Santi, P. M., Russell, C. P., Higgins J. D., and Spriet, J. I.: Modification and statistical analysis of the Colorado Rockfall Hazard Rating System, Eng. Geol., 104, 55-65, doi:10.1016/j.enggeo.2008.08.009, 2009.

Youssef, A. and Maerz, N. H.: Development, justification, and verification of a rock fall hazard rating system, B. Eng. Geol. Environ., 71, 171-186, doi:10.1007/s10064-010-0339-2, 2012. 